\title{
openheart Major adverse cardiac and cerebrovascular event and patients' quality of life after endoscopic vein harvesting as compared with open vein harvest (MAQEH): a pilot study
}

Heyman Luckraz, ${ }^{1}$ Carly Cartwright, ${ }^{1}$ Kumaresan Nagarajan, ${ }^{1}$ Prabhjeet Kaur, ${ }^{1}$ Alan Nevill ${ }^{2}$

To cite: Luckraz H,

Cartwright C, Nagarajan K, et al. Major adverse cardiac and cerebrovascular event and patients' quality of life after endoscopic vein harvesting as compared with open vein harvest (MAQEH): a pilot study. Open Heart 2018;5:e000694. doi:10.1136/ openhrt-2017-000694

Received 6 August 2017 Revised 22 October 2017 Accepted 14 November 2017
CrossMark

'Department of Cardiothoracic Surgery, Heart and Lung Centre, Wolverhampton, UK

${ }^{2}$ Faculty of Education Health and Wellbeing, University of Wolverhampton, Walsall, UK

Correspondence to Dr Heyman Luckraz; HeymanLuckraz@aol.com

\section{ABSTRACT}

Background This is a prospective, comparative, pilot and follow-up (2-year postoperatively) study in patients undergoing coronary artery bypass graft surgery where the long saphenous vein was harvested either by the endoscopic vein harvest (EVH) technique or open vein harvest $(\mathrm{OVH})$ technique. Quality of life (QOL) and major adverse cardiac and cerebrovascular events (MACCE) were assessed.

Methods Alive patients who were initially part of a pilot study when EVH was introduced in our institution were included ( $\mathrm{n}=48 \mathrm{EVH}, \mathrm{n}=49 \mathrm{OVH})$. Patients were sent a QOL questionnaire (SF12v2; 12-item medical outcomes study short form health survey version 2.0), and their cardiologist and general practitioner were contacted to assess MACCE.

Results Median follow-up was 32 and 33 months, respectively. Three patients died (2 EVH, $1 \mathrm{OVH})$. Of the remaining 97 patients who were sent a questionnaire, $76 \%$ patients returned the form. More patients from the EVH group returned the QOL questionnaire (82\% vs $71 \%$ ). Time taken to return to normal daily activities was much shorter in EVH (median 6 (2-30) weeks) compared with OVH (median 9 (2-50) weeks) $(\mathrm{P}<0.05)$. Q0L questionnaire revealed significant difference in physical score at follow-up: 45.3 (10.2) for EVH group and 40.7 (11.0) for OVH group $(\mathrm{P}<0.05)$. There was no difference in mental scores (46.9 (10.5) vs 49.2 (9.1), $P=0.4)$. There were no significant differences in MACCEs including death between the two groups $(12.2 \%$ vs $13.9 \%, P=0.5)$.

Conclusion EVH patients returned to normal daily activities faster than $\mathrm{OVH}$ patients and experienced better physical QOL even after 2 years postoperatively with no increase in MACCE during follow-up.

\section{INTRODUCTION}

Coronary artery bypass grafting (CABG) is recognised as one of the options in the management of patients with coronary artery disease. The short-term and long-term outcomes after CABG are excellent, with a very low mortality. ${ }^{1}$ However, early morbidity from long saphenous vein (LSV) harvesting

\section{Key questions}

What is already known about this subject?

- There have been some concerns regarding major adverse cardiac and cerebrovascular events (MACCEs) after endoscopic vein harvesting (EVH) for coronary artery bypass graft (CABG) surgery. Moreover, quality of life (QOL) after CABG has not been reported when based on long saphenous vein (LSV) harvest technique.

What does this study add?

- This article confirmed that MACCE rates were similar between $\mathrm{EVH}$ and open vein harvest (OVH) techniques for LSV harvest for CABG. In addition, it also showed that the physical aspect of the QOL was significantly better in patients who had EVH for LSV harvest as compared with OVH even 2 years after their surgery.

How might this impact on clinical practice?

- This will serve as a pilot study to generate a randomised control trial to confirm these benefits. Once confirmed, patients will benefit from a better QOL without jeopardising graft patency.

via the open vein harvest $(\mathrm{OVH})$ technique has been high, with leg wound problems reported in a significant number of patients ${ }^{2}$ and leg wound infection in up to $20 \%$. $^{3}$ The development of endoscopic vein harvesting $(\mathrm{EVH})$ has been reported to be associated with better leg wound outcomes. ${ }^{4-6}$ This has been appraised by the National Institute for Health and Care Excellence (NICE), and the latest NICE guidelines have endorsed the use of $\mathrm{EVH}^{7}$

However, there were some initial concerns regarding vein graft patency, ${ }^{8}$ but more recent meta-analyses have not supported these concerns. ${ }^{10} \mathrm{EVH}$ was introduced to our practice as part of service improvement in 
2012. The short-term benefit of EVH as compared with $\mathrm{OVH}$ in our population group has already been proven, and included reduction in leg wound problems and infection, a reduction in leg wound pain and a shorter inhospital stay. ${ }^{11}$ The benefit of EVH has also been supported by the 2014 European Society of Cardiology/European Association for Cardio-Thoracic Surgery guidelines for myocardial revascularisation. ${ }^{12}$

Currently, there are no randomised control trials or large observational reports of quality of life (QOL) after EVH reported in the literature.

The use of EVH is becoming more popular in the Western world. This technology was introduced in our unit a few years ago and is now used in most patients as there is evidence that there has been a significant cost-benefit in our patient group. ${ }^{11}$

This study aimed to assess the intermediate outcome including major adverse cardiac and cerebrovascular event (MACCE) and QOL in the EVH and a matched OVH group.

\section{METHODS}

Patients who were initially part of a prospective matched study comparing the initial experience with EVH with OVH $(n=100)$ were included. These patients were at high risk of developing leg wound problems and had at least two of the following factors: female gender, age over 75 years, diabetes, body mass index $>28 \mathrm{~kg} / \mathrm{m}^{2}$, smoker and presence of peripheral vascular disease. Fifty continuous patients who were suitable for EVH were selected for this modality of LSV harvest and were matched prospectively with 50 continuous patients who had OVH during the same time period. All patients who were still alive at the time of this current study $(n=97)$ were sent a QOL questionnaire (SF12v2), - 12-item medical outcomes study short form health surgey version 2.0 and their cardiologist and general practitioner were contacted to assess MACCE based on clinical assessment but not angiography. EVH was performed using the Vasoview Hemopro II Endoscopic Vessel Harvesting System (Cardiovascular, Wayne, New Jersey, USA). All patients underwent cardiac procedure using the cardiopulmonary bypass machine.

All patients consented for their cardiologist/ general practitioner to be approached to determine if there were any MACCE.

Continuous variables are expressed as mean (SD) or median (minimum, maximum) for Gaussian and skewed distributed data, respectively. Group comparisons were carried out using the t-test or non-parametric (Mann-Whitney U) test accordingly. Categorical data are expressed as percentage, and differences between the two groups were assessed using the $\chi^{2}$ test of independence. Tests were considered significant at $\mathrm{P} \leq 0.05$. Statistical analyses were carried out in SPSS V.20.

\begin{tabular}{|c|c|c|c|}
\hline & EVH $(n=50)$ & OVH $(n=50)$ & $P$ value \\
\hline Age $^{\star}$, years & $67.4(10.6)$ & $68.7(8.6)$ & 0.6 \\
\hline Male $(\%, n)$ & 82,41 & 82,41 & 1 \\
\hline Patients $>75$ years $(\%, n)$ & 24,12 & 22,11 & 0.9 \\
\hline Non-diabetic (\%, n) & 60,30 & 60,30 & 1 \\
\hline Smokers $(\%, \mathrm{n})$ & 18,9 & 14,7 & 0.6 \\
\hline PVD $(\%, n)$ & 26,13 & 24,12 & 0.9 \\
\hline Impaired LVEF $(\%, \mathrm{n})$ & 32,16 & 38,19 & 0.7 \\
\hline $\mathrm{BMI}>28 \mathrm{~kg} / \mathrm{m}^{2}(\%, \mathrm{n})$ & 62,31 & 62,31 & 1 \\
\hline Elective $(\%, n)$ & 54,27 & 58,29 & 0.8 \\
\hline Log Euro score $†$ & $\begin{array}{l}3.92 \\
(0.88,33.63)\end{array}$ & $\begin{array}{l}4.99 \\
(0.88,30.1)\end{array}$ & 0.6 \\
\hline Isolated CABG $(\%, \mathrm{n})$ & 78,39 & 76,38 & 0.9 \\
\hline
\end{tabular}

*Denotes mean (SD).

†Denotes median (minimum, maximum).

$\mathrm{BMI}$, body mass index; CABG, coronary artery bypass

graft surgery; EVH, endoscopic vein harvest; LVEF, left ventricular ejection fraction; OVH, open vein harvest; PVD, peripheral vascular disease.

\section{RESULTS}

There were no significant differences in patients' preoperative characteristics (table 1 ).

The median follow-up was 32 (28-43) months and 33 (28-42) months for the EVH and OVH groups, respectively $(\mathrm{P}=0.6)$. Three patients died $(2 \mathrm{EVH}, 1 \mathrm{OVH})$ during that period. Of the remaining 97 patients who were sent a questionnaire, $76 \%$ patients returned the form. Interestingly more patients from the EVH group returned the QOL questionnaire (82\% vs $71 \%$ ).

The time taken to return to normal daily activities was much shorter in EVH (median 6 (2-30) weeks) compared with OVH (median $9(2-50)$ weeks) $(\mathrm{P}<0.05)$. The QOL questionnaire revealed significant difference in physical score at follow-up: 45.3 (10.2) for EVH group and 40.7 (11.0) for OVH group $(\mathrm{P}<0.05)$ (figure 1$)$. There was no difference in mental scores (46.9 (10.5) vs 49.2 (9.1), $\mathrm{P}=0.4$ ). There were no significant differences in MACCEs including death between the two groups $(12.2 \%$ vs $13.9 \%$, $\mathrm{P}=0.5$ ). The MACCEs reported for each group are listed in table 2.

\section{DISCUSSION}

This is the first report on QOL post-CABG taking into account the modality of LSV harvest. Previously, QOL post-CABG has been compared with percutaneous coronary intervention, ${ }^{13} 14$ where no significant differences were reported between the two groups. The effect of on-pump and off-pump CABG on QOL has also been assessed, and it has been shown that there were no significant differences between these two groups. ${ }^{15}$ Longitudinal QOL assessment showed an important improvement in QOL after CABG. ${ }^{16}$ The effects of age on QOL in 


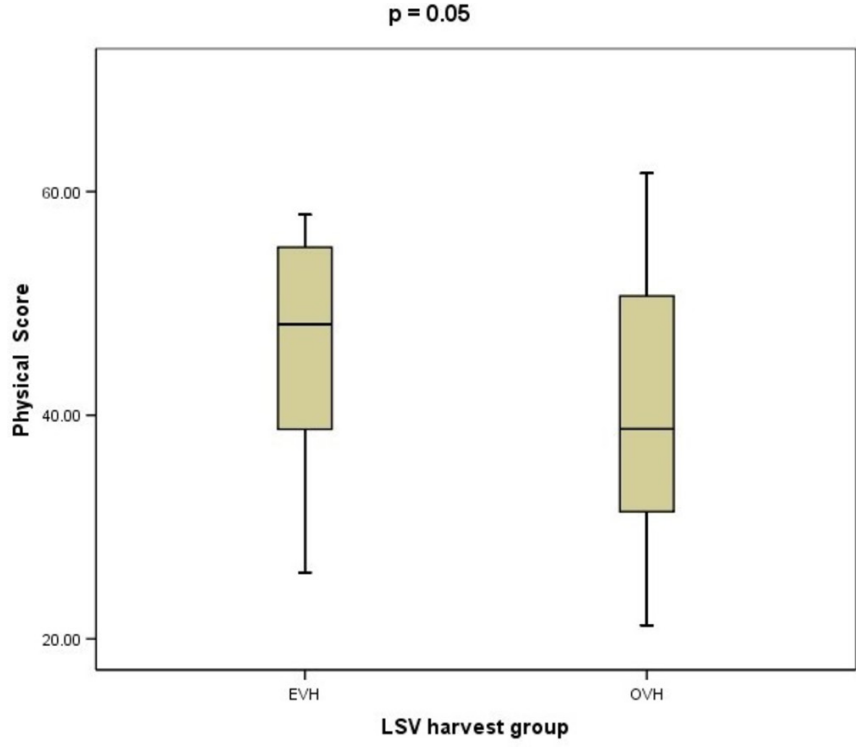

Figure 1 Physical scores (SF12v2 - 12-item medical outcomes study short form helath survey version 2.0) of the EVH and OVH groups. EVH, endoscopic vein harvest; LSV, long saphenous vein; $\mathrm{OVH}$, open vein harvest.

CABG have also been documented in the literature, ${ }^{17} 18$ with the greatest benefit seen in the more elderly population. This current study assessed the QOL as a function of the type of LSV harvest (EVH vs OVH). However, there was not a preprocedure QOL assessment, but given that the patients were selected continuously and that the two groups were matched on their preoperative characteristics, the risk of any bias would have been minimal. The

\begin{tabular}{|c|c|}
\hline MACCEs & Time to event \\
\hline \multicolumn{2}{|l|}{ EVH group $(n=41)$} \\
\hline Death & $\begin{array}{l}\text { Immediate } \\
\text { postoperatively: multiorgan failure }\end{array}$ \\
\hline Death & $\begin{array}{l}19 \text { months postoperatively: } \\
\text { pneumonia }\end{array}$ \\
\hline Angina & 10 months postoperatively \\
\hline Decompensated cardiac failure & $\begin{array}{l}6 \text { months postoperatively (poor } \\
\text { LVEF preoperatively) }\end{array}$ \\
\hline Right occipital small infarct & 2 weeks postoperatively \\
\hline \multicolumn{2}{|l|}{ OVH group $(n=36)$} \\
\hline Death & $\begin{array}{l}34 \text { months postoperatively: heart } \\
\text { failure }\end{array}$ \\
\hline $\begin{array}{l}\text { AF with decompensated heart } \\
\text { failure }\end{array}$ & 3 months postoperatively \\
\hline Angina-stenosis of $0 \mathrm{M}$ & 6 weeks postoperatively \\
\hline Intracerebral haemorrhage & 4 weeks postoperatively \\
\hline Heart failure & 3 months postoperatively \\
\hline
\end{tabular}

$A F$, atrial fibrillation; $E V H$, endoscopic vein harvest; LVEF, left ventricular ejection fraction; MACCE, major adverse cardiac and cerebrovascular event; OM, obtuse marginal artery; OVH, open vein harvest.
SF12v2 assessments showed a clear benefit at the time of follow-up (median around 32 months) in terms of physical performance, when EVH was used. There was no significant impact on mental performance at follow-up between the two techniques (EVH or $\mathrm{OVH})$.

Persistent leg wound problems even months after CABG have previously been reported, ${ }^{19}$ with harvest site pain, numbness and dysaesthesia. Similar findings were reported by Zhu $e t a l^{2}$ as part of a subanalysis in the RAPCO (Radial Artery Patency and Clinical Outcomes) trial. In the initial study for the current study group, worst pain was also documented in the $\mathrm{OVH}$ arm when compared with the EVH arm. ${ }^{11}$

There have been some concerns regarding the patency of LSV grafts when EVH is used. These were initially highlighted in the substudy of the ROOBY (Randomized On/ Off Bypass) trial ${ }^{8}$ and also with the PREVENT IV (Prevention of autogenous vein graft failure in coronary artery bypass procedures) trial. ${ }^{9}$ However, more recent data with the latest EVH technology suggested that LSV graft patency is not affected as compared with OVH. ${ }^{1020}$ Similar outcomes have been reported when the LSV had been harvested by EVH for lower limb vascular procedures. ${ }^{21}$ In the current study, only a small percentage of patients post-CABG had either an ischaemic event or evidence of blocked grafts on angiography: 2.4\% (1/41) for EVH and $2.8 \%(1 / 36)$ for $\mathrm{OVH}$.

Overall MACCE rates in this current study were $12.2 \%$ for $\mathrm{EVH}$ vs $13.9 \%$ for OVH. These rates are fairly similar to the rate reported in the NOBLE (coronary artery bypass grafting vs drug eluting stent percutaneous coronary angioplasty in the treatment of unprotected left main stenosis) trial: $19 \%$ for $\mathrm{CABG}$ at 5 years. ${ }^{22}$ Thus, within this small series, EVH use was not associated with an increased MACCE rate.

\section{Limitations}

This was a single-centre, pilot study. Moreover, preoperative QOL data were not available for both groups of patients. Treatment assignments were not blinded. Knowledge of treatment status may have affected QOL responses. QOL measures reflect a subjective assessment of health status; participants from diverse cultures may attach different significance to symptoms/limitations. Because of lack of randomisation, such differences could have affected the scores. Many biological and socioeconomic factors not included in this analysis may also impact QOL.

\section{CONCLUSION}

EVH patients returned to normal daily activities faster than $\mathrm{OVH}$ patients. The former also experienced better physical QOL even after 2years postoperatively with no increase in MACCE during follow-up when compared with OVH patients. However, given that this was only a pilot study involving a small number of patients, a larger 
randomised control trial would be beneficial to confirm these findings.

Acknowledgements We would like to express our gratitude to the staff (nurses, perfusionists, paramedical staff, junior doctors, anaesthetists and surgeons) of the cardiothoracic surgical unit of the Heart and Lung Centre, Wolverhampton, for their help and support during the initial assessment of the endoscopic vein harvesting service.

Contributors All the authors listed for this manuscript have been involved in some of the following: study design, protocol writing, ethics submission, data collection, data analysis and manuscript writing. They all have reviewed the final version of the manuscript and are in agreement with its content.

Funding This work was supported by Maquet (Sunderland, UK) with a research grant, which was used to cover the cost for the research nurse.

Competing interests $\mathrm{HL}$ has received educational grant from Maquet to attend cardiothoracic surgical meetings.

Ethics approval This study is in agreement with the Hospital's Research and Development Department and received ethical approval (NRES Committee South Central - Oxford, Ref 15/SC/0178).

Provenance and peer review Not commissioned; externally peer reviewed.

Data sharing statement Data for this study are available on request to the R\&D Department at The Royal Wolverhampton NHS Trust.

Open Access This is an Open Access article distributed in accordance with the Creative Commons Attribution Non Commercial (CC BY-NC 4.0) license, which permits others to distribute, remix, adapt, build upon this work non-commercially, and license their derivative works on different terms, provided the original work is properly cited and the use is non-commercial. See: http://creativecommons.org/ licenses/by-nc/4.0/

C Article author(s) (or their employer(s) unless otherwise stated in the text of the article) 2018. All rights reserved. No commercial use is permitted unless otherwise expressly granted.

\section{REFERENCES}

1. Serruys PW, Morice MC, Kappetein AP, et al. Percutaneous coronary intervention versus coronary-artery bypass grafting for severe coronary artery disease. N Engl J Med 2009;360:961.72.

2. Zhu YY, Hayward PA, Hadinata IE, et al. Long-term impact of radial artery harvest on forearm function and symptoms: a comparison with leg vein. J Thorac Cardiovasc Surg 2013;145:412-9.

3. Paletta CE, Huang DB, Fiore AC, et al. Major leg wound complications after saphenous vein harvest for coronary revascularization. Ann Thorac Surg 2000;70:492-7.

4. Andreasen JJ, Nekrasas V, Dethlefsen C. Endoscopic vs open saphenous vein harvest for coronary artery bypass grafting: a prospective randomized trial. Eur J Cardiothorac Surg 2008;34:384-9.

5. Lopes RD, Hafley GE, Allen KB, et al. Endoscopic versus open veingraft harvesting in coronary-artery bypass surgery. $N$ Engl $J$ Med 2009;361:235-44.

6. Markar SR, Kutty R, Edmonds L, et al. A meta-analysis of minimally invasive versus traditional open vein harvest technique for coronary artery bypass graft surgery. Interact Cardiovasc Thorac Surg 2010;10:266-70.

7. Simek M, Bruk V, Nemec P, et al. [Endoscopic saphenous vein harvesting for coronary artery bypass grafting]. Rozhl Chir 2006;85:211-5.

8. Edgerton JR, Dewey TM, Magee MJ, et al. Conversion in off-pump coronary artery bypass grafting: an analysis of predictors and outcomes. Ann Thorac Surg 2003;76:1138-43.

9. Harskamp RE, Alexander JH, Schulte PJ, et al. Vein graft preservation solutions, patency, and outcomes after coronary artery bypass graft surgery: follow-up from the PREVENT IV randomized clinical trial. JAMA Surg 2014;149:798-805.

10. Deppe AC, Liakopoulos OJ, Choi YH, et al. Endoscopic vein harvesting for coronary artery bypass grafting: a systematic review with meta-analysis of 27,789 patients. J Surg Res 2013;180:114-24.

11. Luckraz $\mathrm{H}$, Kaur P, Bhabra M, et al. Endoscopic vein harvest in patients at high risk for leg wound complications: a costbenefit analysis of an initial experience. Am J Infect Control 2016;44:1606-10.

12. Kolh P, Windecker S, Alfonso F, et al. 2014 ESC/EACTS Guidelines on myocardial revascularization: the task force on myocardial revascularization of the European Society of Cardiology (ESC) and the European Association for Cardio-Thoracic Surgery (EACTS). Developed with the special contribution of the European Association of Percutaneous Cardiovascular Interventions (EAPCI). Eur $J$ Cardiothorac Surg 2014;46:517-92.

13. Yazdani-Bakhsh R, Javanbakht M, Sadeghi M, et al. Comparison of health-related quality of life after percutaneous coronary intervention and coronary artery bypass surgery. ARYA Atheroscler 2016;12:124-31.

14. Maznyczka AM, Howard JP, Banning AS, et al. A propensity matched comparison of return to work and quality of life after stenting or coronary artery bypass surgery. Open Heart 2016;3:e000322.

15. Lamy A, Devereaux PJ, Prabhakaran D, et al. Five-year outcomes after off-pump or on-pump coronary-artery bypass grafting. $N$ Engl $J$ Med 2016;375:2359-68.

16. Westerdahl E, Jonsson M, Emtner M. Pulmonary function and health-related quality of life 1-year follow up after cardiac surgery. $J$ Cardiothorac Surg 2016;11:99.

17. Peric V, Jovanovic-Markovic S, Peric D, et al. Quality of life in patients of different age groups before and after coronary artery bypass surgery. Ann Thorac Cardiovasc Surg 2015;21:474-80.

18. Caceres M, Cheng W, De Robertis M, et al. Survival and quality of life for nonagenarians after cardiac surgery. Ann Thorac Surg 2013;95:1598-602.

19. Dick F, Hristic A, Roost-Krähenbühl E, et al. Persistent sensitivity disorders at the radial artery and saphenous vein graft harvest sites: a neglected side effect of coronary artery bypass grafting procedures. Eur J Cardiothorac Surg 2011;40:221-6.

20. Raja SG, Sarang Z. Endoscopic vein harvesting: technique, outcomes, concerns \& controversies. J Thorac Dis 2013;5(Suppl 6):S630-7.

21. Khan SZ, Rivero M, McCraith B, et al. Endoscopic vein harvest does not negatively affect patency of great saphenous vein lower extremity bypass. J Vasc Surg 2016;63:1546-54.

22. Mäkikallio T, Holm NR, Lindsay M, et al. Percutaneous coronary angioplasty versus coronary artery bypass grafting in treatment of unprotected left main stenosis (NOBLE): a prospective, randomised, open-label, non-inferiority trial. Lancet 2016;388:2743-52. 